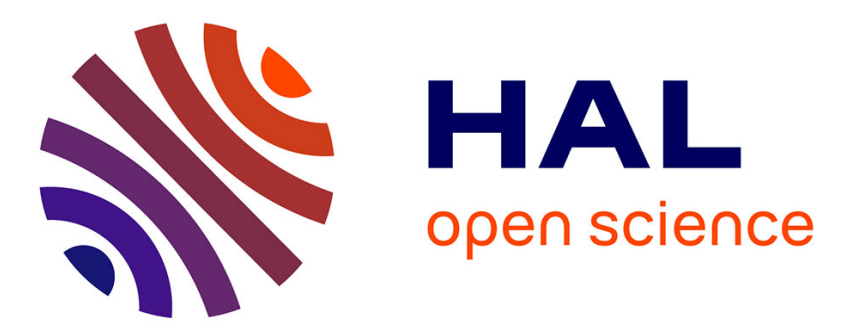

\title{
From well-defined poly(N-acryloylmorpholine)-stabilized nanospheres to uniform mannuronan- and guluronan-decorated nanoparticles by RAFT polymerization-induced self-assembly
}

\author{
Isabelle Chaduc, Eric Reynaud, Lionel Dumas, Luca Albertin, Franck
}

d'Agosto, Muriel Lansalot

\section{To cite this version:}

Isabelle Chaduc, Eric Reynaud, Lionel Dumas, Luca Albertin, Franck d'Agosto, et al.. From welldefined poly(N-acryloylmorpholine)-stabilized nanospheres to uniform mannuronan- and guluronandecorated nanoparticles by RAFT polymerization-induced self-assembly. Polymer, 2016, 106, pp.218228. 10.1016/j.polymer.2016.08.072 . hal-01576608

\section{HAL Id: hal-01576608 \\ https://hal.science/hal-01576608}

Submitted on 8 Oct 2021

HAL is a multi-disciplinary open access archive for the deposit and dissemination of scientific research documents, whether they are published or not. The documents may come from teaching and research institutions in France or abroad, or from public or private research centers.
L'archive ouverte pluridisciplinaire HAL, est destinée au dépôt et à la diffusion de documents scientifiques de niveau recherche, publiés ou non, émanant des établissements d'enseignement et de recherche français ou étrangers, des laboratoires publics ou privés. 


\title{
From well-defined poly( $N$-acryloylmorpholine)-stabilized nanospheres to uniform mannuronan- and guluronan-decorated nanoparticles by RAFT polymerization-induced self-assembly.
}

Isabelle Chaduc, ${ }^{a}$ Eric Reynaud, ${ }^{\mathrm{b}}$ Lionel Dumas, ${ }^{\mathrm{b}}$ Luca Albertin, ${ }^{\mathrm{b}},{ }^{\ddagger}$ Franck D'Agosto, ${ }^{\mathrm{a}, *}$ Muriel Lansalot ${ }^{\text {a,* }}$

a Université de Lyon, Univ. Lyon 1, CPE Lyon, CNRS UMR 5265, Laboratoire de Chimie, Catalyse, Polymères et Procédés (C2P2), LCPP Team, Bat 308F, 43 Bd du 11 Novembre 1918, F-69616 Villeurbanne, France

${ }^{b}$ Centre de Recherches sur les Macromolécules Végétales (CERMAV-CNRS), Grenoble, France.

‡ Present address: Laboratoire de Chimie et Biologie des Métaux, UMR 5249 - Université Grenoble Alpes, CEA, CNRS, 17 rue des Martyrs, 38054 Grenoble, France

franck.dagosto@univ-lyon1.fr; muriel.lansalot@univ-lyon1.fr

\begin{abstract}
Non-ionic poly(N-acryloylmorpholine) (PNAM)-decorated polystyrene (PS) particles were synthesized by polymerization-induced self-assembly (PISA) in emulsion, mediated by the reversible additionfragmentation chain transfer (RAFT) technique, in a one-pot/two-step process. PNAM was first prepared by RAFT polymerization in water using 4-cyano-4-thiothiopropylsulfanyl pentanoic acid (CTPPA) as chain transfer agent. Chain extension of PNAM by a PS block was then accomplished by the polymerization of styrene in water. Spherical nanoparticles (number-average diameter $<60 \mathrm{~nm}$ ) exclusively composed of well-defined PNAM- $b$-PS amphiphilic block copolymers $(1.1<\theta<1.4)$ were successfully obtained under a broad range of conditions (PNAM number-average molar mass of 2000, 4000 and $8000 \mathrm{~g} \mathrm{~mol}^{-1}$, and average polymerization degree of the PS block from 150 up to 1600 ). Mannuronan (Man $\left.A_{17}\right)$ - and guluronan ( $\mathrm{GuI}_{20}$ )-decorated nanoparticles were further synthesized according to a similar PISA process. Glycuronan macromonomers carrying a methacrylate polymerizable group ( $\mathrm{ManA}_{17} \mathrm{MA}$ or $\mathrm{Gul} \mathrm{A}_{20} \mathrm{MA}$ ) were first copolymerized with $\mathrm{N}$-acryloylmorpholine (NAM) under successful RAFT control using CTPPA. The resulting hydrophilic $\mathrm{P}\left(\mathrm{NAM}-\mathrm{co}-\mathrm{ManA}_{17} \mathrm{MA}\right)$ and $\mathrm{P}\left(\mathrm{NAM}-\mathrm{co}-\mathrm{Gul} \mathrm{A}_{20} \mathrm{MA}\right)$ macroRAFT agents were then used to polymerize styrene in water. Spherical glycuronan-decorated nanoparticles composed exclusively of amphiphilic block copolymers were successfully obtained for both glycuronan-based macroRAFT agents.
\end{abstract}




\section{Introduction}

The self-assembly of amphiphilic block copolymers in water is a very active field of research pioneered and popularized by Eisenberg, Discher and Zhang. ${ }^{[1-5]}$ It enables the preparation of aggregates with morphologies ranging from spherical, to rods, lamellae, vesicles and large compound micelles ${ }^{[6]}$ that find very promising application in nanoscience. ${ }^{[7,8]}$ In a typical procedure (the co-solvent method) ${ }^{[2,6]}$ the block copolymer is dissolved in a water-miscible common solvent (i.e. a good solvent for all blocks) and water is slowly added to desolvate the hydrophobic blocks and induce their aggregation into the hydrophobic part of the aggregates. Water addition is continued until well after the critical water content at which aggregation starts, and the aggregates are quenched in an excess of water to freeze the kinetic processes and morphologies. The common solvent is finally eliminated by dialysis of the resulting dispersion against water. The final morphology will be dictated by various parameters such as the nature and molar mass of the hydrophilic and hydrophobic blocks, the composition (i.e. hydrophile / hydrophobe ratio) and concentration of the block copolymer, the nature of the common solvent, the water content before quenching, the $\mathrm{pH}$ and/or the temperature. Although widespread, this process is unsuitable for routine and industrial applications since (i) it requires large amounts of water and long equilibration times and (ii) it invariably leads to dilute dispersions of low solids content (typically $<2 \mathrm{wt} \%$ ).

The large scale development of high performance materials based on block copolymer nanoparticles will depend on the availability of simple procedures to self-assemble and isolate large amounts of the targeted structures. In the case of water-borne nanoparticles, the so-called Polymerization-Induced SelfAssembly (PISA) process has considerably eased their preparation by combining the synthesis and selfassembly of amphiphilic block copolymers in a single operation. ${ }^{[9-14]}$ It relies on the chain extension of living hydrophilic polymer chains with a hydrophobic monomer via controlled radical polymerization directly in water. Either performed under dispersion or emulsion polymerization, PISA allows to build phase diagrams ${ }^{[15,16]}$ similar to those previously depicted for the self-assembly of preformed amphiphilic block copolymers ${ }^{[6]}$ but obtained here under much more favorable conditions, i.e. at high solids content and short reaction times. Simply varying the relative fraction of each block in the copolymer usually dictates the final morphology of the aggregates, although kinetically trapped morphologies are quite common. Accordingly, most of the studies dedicated to PISA and targeting the formation of spheres, fibers or vesicles depict the effect of the increase of the molar mass of the hydrophobic block on the morphology of the final nano-objects, which most of the time follows the spheres - to worms - to vesicles transition ${ }^{[9-13,17,18]}$ previously described by studies with the co-solvent method. ${ }^{[6]}$

In our laboratory we are investigating Polymerization-Induced Self-Assembly in emulsion for the facile synthesis of polymer nano-objects with original and well-defined surface chemistry. ${ }^{[19-22]}$ In this context, an original two-step one-pot RAFT-mediated PISA process was developed ${ }^{[23]}$ that was successfully applied 
to the synthesis of polystyrene particles stabilized by various hydrophilic and $\mathrm{pH}$-sensitive polymers. Thus, poly(acrylic acid), ${ }^{[24]}$ poly(methacrylic acid) ${ }^{[25]}$ or poly(methacrylic acid-co-poly(ethylene oxide) methyl ether methacrylate) ${ }^{[26]}$ macroRAFT agents were first formed in water, and then directly used to mediate the emulsion polymerization of styrene in the same reaction vessel. It is worth noting that this strategy requires a very good control over the polymerization of the hydrophilic monomer(s) up to complete conversion. ${ }^{[23]}$

Alginate is a family of binary heteropolysaccharides produced by brown algae $\mathrm{2}^{[27]}$ and by some soil bacteria. ${ }^{[28]}$ They are linear unbranched copolymers of $(1 \rightarrow 4)$-linked $\beta$-D-mannuronic acid (ManA) and $\alpha$ L-guluronic acid (GulA) residues distributed in long homopolymeric blocks, i.e. ( $1 \rightarrow 4)-\beta$-D-mannuronan $\left(M a n A_{x}\right)$ and $(1 \rightarrow 4)$ - $\alpha$-L-guluronan (GulA $A_{x}$, where $X$ is the degree of polymerization), and in shorter, mostly alternating, copolymer blocks. ${ }^{[27,29]}$ Since they are entirely composed of glycuronic acid residues, alginates are glycuronans. A striking feature of alginates is their ability to undergo ionotropic gelation, i.e. to form transparent hydrogels upon addition of some divalent cations in aqueous solution (e.g. $\mathrm{Ca}^{2+}$, $\mathrm{Ba}^{2+}, \mathrm{Sr}^{2+}$ and $\left.\mathrm{Zn}^{2+}\right)$. This is due to the intermolecular complexation of said ions by (1 $\left.\rightarrow 4\right)-\alpha-\mathrm{L}$-guluronan and alternating sequences ${ }^{[30-32]}$ and to the formation of junction zones. Said complexation is the basis of the high affinity and selectivity of binding of alginates for some divalent metal ions ${ }^{[30,33-35]}$ which is exploited for the sequestration of heavy metals ${ }^{[36-39]}$ and radioactive isotopes in solution. ${ }^{[40-42]}$ Another attractive characteristic of alginates is the possibility to extract their constituting blocks by controlled hydrolysis and selective precipitation. ${ }^{[43,44]}$ This way homopolymeric guluronan and mannuronan samples with number-average degree of polymerization $X_{n}=30 \pm 10$ and low molar mass dispersity $(\theta \leq 1.2)$ can be obtained in good yield on a multi-gram scale. These oligosaccharides are stiff, negatively charged at $\mathrm{pH} \geq 4$, and retain the ion-binding properties of the parent homopolysaccharides. Concerning the biological activity of $(1 \rightarrow 4)$ - $\beta$-D-mannuronan and $(1 \rightarrow 4)$ - $\alpha$-L-guluronan, it is demonstrated that they are potent immune-modulators. ${ }^{[45,46]}$

To the best of our knowledge, only four previous papers describe the synthesis of carbohydratedecorated nanoparticles by RAFT-mediated PISA in dispersed aqueous media, and then only neutral monosaccharides were considered. Bernard et al. ${ }^{[4]]}$ reported the use of a xanthate end-functionalized dextran (dextran-CTA, functionalization rate ca. 30\%) to mediate vinyl acetate (VAc) emulsion polymerization. The in situ formation of dextran- $b$-PVAc block copolymers afforded particle stabilization and monodisperse PVAc latex particles were obtained with fast kinetics for low amounts of dextran-CTA (2-4 wt\%). Ting et al. carried out the emulsion polymerization of styrene in the presence of hydrophilic poly((2-methacrylamido)-glucopyranose) prepared by $\mathrm{RAFT}^{[48]}$ leading to the formation of spherical glyco-particles bearing glucose units. Very recently, Hatton et al. ${ }^{[49]}$ used hydrophilic dithioesterfunctionalized xyloglucan (XG) chains for the synthesis of poly(methyl methacrylate) (PMMA) particles by RAFT emulsion polymerization. The nanoparticles were subsequently adsorbed onto cellulose through 
non-covalent interactions. Ladmiral et al. used hydrophilic polymer chains containing galactose units for the RAFT dispersion PISA of 2-hydroxypropyl methacrylate (HPMA). ${ }^{[50]}$ By varying the molar mass of the HPMA block and the solids content of the dispersion, glycopolymer-decorated nanospheres, worm-like micelles and vesicles were obtained. Concerning glycuronan-stabilized polymer particles, those described so $\mathrm{far}^{[51,52]}$ are micrometric in size and stabilized by the physical adsorption of high molar mass alginates. Very recently, Kapishon and coworkers reported the synthesis of alginate-based micelles by a single electron transfer living radical polymerization (SET-LRP) PISA process. ${ }^{[53]}$ Non-uniform alginate fragments of ca. $20000 \mathrm{~g} \mathrm{~mol}^{-1}$ were obtained by the random depolymerization of native alginate and partially esterified with bromoisobutyryl initiator groups. Graft chains of poly(methyl methacrylate) were then grown by SET-LRP in homogeneous water/MeOH mixtures, leading to the in situ formation of alginate-gPMMA copolymers. The latter self-assembled into micelles with sizes ranging from $50 \mathrm{~nm}$ to $300 \mathrm{~nm}$ and Poly values comprised between 0.06 and 0.20 (after dialysis), depending on the initial conditions of the polymerization.

In this paper, we first report the synthesis of polystyrene particles by the one-pot PISA process ${ }^{[23]}$ utilizing for the first time a non-ionic hydrophilic monomer ( $N$-acryloylmorpholine, NAM). The RAFT homopolymerization of NAM in water and the chain extension of the resulting macromolecules with styrene in emulsion polymerization are first investigated in details under a broad range of conditions. We then describe the preparation of $(1 \rightarrow 4)-\beta$-D-mannuronan- and $(1 \rightarrow 4)$ - $\alpha$-L-guluronan-decorated nanospheres by PISA. Uniform guluronan and mannuronan samples $(\theta \leq 1.2)$ were functionalized with a polymerizable group at their reducing end and the resulting macromonomers were copolymerized with NAM by aqueous RAFT. The resulting hydrophilic macroRAFT agents were then used to mediate the emulsion polymerization of styrene in the same reactor (Scheme 1). 
a)
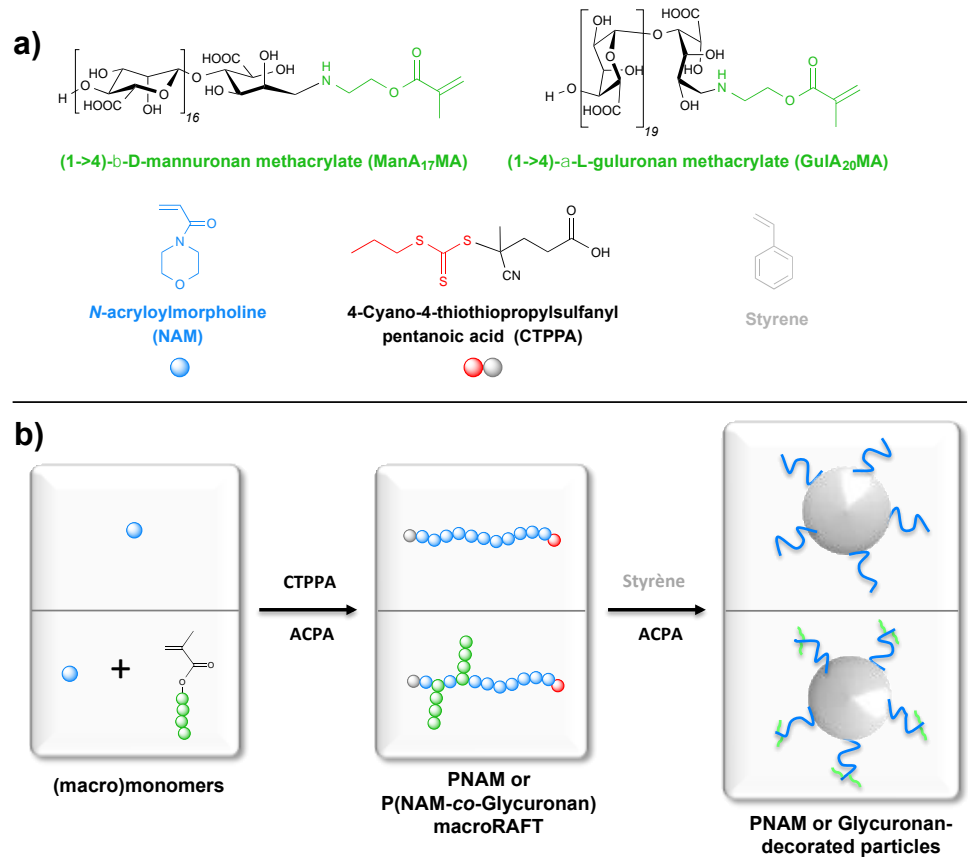

Scheme 1. a) Chemical structure, name and acronym of the main (macro)molecules used in this study. b) Synthetic scheme depicting the synthesis of PNAM and glycuronan-decorated particles (ACPA stands for 4,4'-azobis(4cyanopentanoic acid)).

\section{Experimental}

Materials. 4,4'-azobis(4-cyanopentanoic acid) (ACPA, Fluka, >98\%), sodium hydrogen carbonate $\left(\mathrm{NaHCO}_{3}\right.$, Aldrich, $>99.7 \%$ ) and $\mathrm{N}$-acryloylmorpholine (NAM, Aldrich 97\%) were used as received. Styrene (S, Aldrich, 99\%) was purified by removing the inhibitor by filtration with aluminium oxide. 4-Cyano-4thiothiopropylsulfanyl pentanoic acid (CTPPA) was obtained by reaction of ACPA with bis(thiobenzoyl) and bis(propylsulfanylthiocarbonyl) disulfides according to the literature. ${ }^{[54]}$ (1 $\left.\rightarrow 4\right)-\beta$-D-mannuronan $\left(\mathrm{ManA}_{17}\right)$ and $(1 \rightarrow 4)$ - $\alpha$-L-guluronan $\left(\mathrm{Gul}_{20}\right)$ were obtained from Elicityl SA (Crolles, France) as sodium salts and were characterized by ${ }^{1} \mathrm{H}$ NMR and SEC-MALLS for their composition, degree of polymerization and dispersity index (Table 1).

Table 1: Characterization of the polysaccharides used in this study.

\begin{tabular}{|lccccccc|}
\hline Polysaccharide & $\boldsymbol{X}_{\mathbf{n}}{ }^{\mathbf{b}}$ & $\boldsymbol{D}^{\mathrm{a}}$ & $\boldsymbol{F}_{\mathbf{M}}$ & $\boldsymbol{F}_{\mathbf{G}}$ & $\boldsymbol{F}_{\mathbf{M M}}$ & $\boldsymbol{F}_{\mathbf{M G}}$ & $\boldsymbol{F}_{\mathrm{GG}}$ \\
\hline ManA $_{17}$ & 17 & 1.07 & 0.92 & 0.08 & 0.81 & 0.07 & 0.03 \\
GulA $_{20}$ & 20 & 1.20 & 0.10 & 0.90 & 0.06 & 0.05 & 0.88 \\
\hline
\end{tabular}

$X_{\mathrm{n}}$ is the number-average degree of polymerization; $\Theta$ is the dispersity; $F_{\mathrm{M}}$ and $F_{\mathrm{G}}$ are the molar fraction of $\beta$-D-mannuronic acid and $\alpha$-L-guluronic acid units in the polysaccharide; $F_{\mathrm{MM}}, F_{\mathrm{MG}}$ and $F_{\mathrm{GG}}$ are the frequencies of the corresponding diad sequences estimated by ${ }^{1} \mathrm{H}$ NMR. aSEC-MALLS. bFrom the ratio between the area of the reducing end anomeric protons signal and that of all anomeric protons (i.e. internal glycosidic plus reducing end) in ${ }^{1} \mathrm{H}$ NMR. 
Glycuronan ${ }^{[55],[56]}$ macromonomers were prepared according to the previously described methods. ${ }^{\left[{ }^{[5-59]}\right.}$ Briefly, (1 $\rightarrow 4)$ - $\beta$-D-mannuronan methacrylate $\left(\mathrm{ManA}_{17} \mathrm{MA}\right)$ and $(1 \rightarrow 4)$ - $\alpha$-L-guluronan methacrylate $\left(G u l A_{20} M A\right)$ were prepared in one step by reductive amination of the starting oligosaccharide with an excess of 2 -aminoethyl methacrylate hydrochloride ( $90 \%$, Aldrich). It is worth noting that the final products contained varying amounts of non-functionalized oligosaccharide. The degree of functionalization $Q$ was determined by ${ }^{1} H$ NMR, and these products were directly used for polymerization experiments. In fact oligosaccharides not functionalized with an ethylenic group are inert towards the secondary and tertiary carbon-centred radicals involved in this study. These will not take part to polymerization and will not be incorporated into the final nanoparticles. The degree of functionalization of the macromonomers was taken into account for stoichiometric calculations.

\section{One-pot procedure for the synthesis of polymer particles by emulsion polymerization in the presence of macroRAFT agent.}

Step 1: Synthesis of macroRAFT agents in water. In all cases CTPPA was used as the chain transfer agent and ACPA as the radical initiator. In a typical experiment (PNAM1), $179 \mathrm{mg}$ of CTPPA $\left(6.45 \times 10^{-4} \mathrm{~mol}\right)$ and $18 \mathrm{mg}$ of ACPA ( $\left.6.45 \times 10^{-5} \mathrm{~mol}\right)$ were added to a two-necked round-bottom flask and dissolved in $3 \mathrm{~mL}$ of water. $2.47 \mathrm{~g}$ of NAM $\left(1.70 \times 10^{-2} \mathrm{~mol}\right)$ dissolved in $7 \mathrm{~mL}$ of water were introduced inside the reactor. $255 \mathrm{mg}$ of 1,3,5-trioxane $\left(2.83 \times 10^{-3} \mathrm{~mol}\right)$ was added as an internal reference for NMR analysis. After deoxygenation by nitrogen bubbling for $30 \mathrm{~min}$, the resulting mixture was immersed in an oil bath thermostated at $80^{\circ} \mathrm{C}$, which corresponded to time zero of the polymerization. The regular withdrawal of samples allowed following the monomer conversion as a function of time and the evolution of molar masses and molar mass distributions as a function of monomer conversion. The monomer conversion was determined by ${ }^{1} \mathrm{H}$ NMR spectroscopy of the crude reaction medium diluted with $\mathrm{D}_{2} \mathrm{O}$ by the relative integration of the protons of 1,3,5-trioxane and the vinylic protons of the monomer. The same procedure was followed for the synthesis of glycuronan-based macroRAFT agents using a mixture of NAM with either $\mathrm{ManA}_{17} \mathrm{MA}$ (3800 $\mathrm{g} \mathrm{mol}^{-1}, Q=62 \mathrm{wt} \%$ ) or GulA $\mathrm{A}_{20} \mathrm{MA}\left(4210 \mathrm{~g} \mathrm{~mol}^{-1}, Q=62 \mathrm{wt} \%\right.$ ), respectively macroRAFT agents $\mathrm{M} 1$ and $\mathrm{G} 1$ in Table 3.

Step 2: Emulsion polymerization procedure. Polymerization of styrene was performed at $80^{\circ} \mathrm{C}$ in a twonecked round-bottom flask equipped with a condenser. In a typical experiment (Latex B1), $2.50 \mathrm{~g}$ of styrene was added to the solution of hydrophilic macroRAFT agent PNAM1, and the water content was adjusted so that the final concentration of styrene and macroRAFT were $2.4 \mathrm{~mol} \mathrm{~L}^{-1}$ and $1.6 \times 10^{-2} \mathrm{~mol} \mathrm{~L}^{-}$ 1 , respectively. $1 \mathrm{~mL}$ of an aqueous solution of ACPA ( $9.2 \mathrm{mg}$ - neutralized by $\mathrm{NaHCO}_{3}$ ) was added to the reaction mixture. The medium was purged with nitrogen during $30 \mathrm{~min}$. The immersion of the round 
bottom flask in an oil bath thermostated at $80^{\circ} \mathrm{C}$ corresponded to time zero of the polymerization. For each experiment, samples were periodically withdrawn to follow conversion by gravimetric analysis. The average molar masses (number-average molar mass $M_{n}$ and weight-average molar mass $M_{w}$ ) and the molar mass dispersity $\left(\Theta=M_{w} / M_{n}\right)$ were determined by SEC.

\section{Analytical techniques.}

NAM and macromonomer conversions were determined by ${ }^{1} \mathrm{H}$ NMR spectroscopy in $\mathrm{D}_{2} \mathrm{O}$ at room temperature (Bruker DRX 300). For the polymerization of styrene in water, monomer consumption was followed by gravimetric analysis of samples withdrawn from the polymerization medium at different times.

Size exclusion chromatography (SEC) measurements for PNAM and PNAM- $b$-PS were performed in THF, referred to as SEC-THF, at $40^{\circ} \mathrm{C}$ at a flow rate of $1 \mathrm{~mL} \mathrm{~min}^{-1}$, using toluene as a flow rate marker. Before analysis, the polymers were modified by methylation of the carboxylic acid end groups using trimethylsilyl diazomethane. ${ }^{[60]}$ They were analyzed at a concentration of $3 \mathrm{mg} \mathrm{mL}^{-1}$ after filtration through a $0.45 \mu \mathrm{m}$ pore-size membrane. The separation was carried out on three columns from Malvern Instruments [T6000M General Mixed Org $(300 \times 8 \mathrm{~mm})$ ]. The setup (Viscotek TDA305) was equipped with a refractive index (RI) detector $(\lambda=670 \mathrm{~nm}) . M_{n}$ and $\Theta$ were derived from the RI signal by a calibration curve based on polystyrene standards (Polymer Laboratories).

Mannuronan- or guluronan-based copolymers were analyzed by an aqueous SEC (ASEC) system composed of an Isochrom LC pump with a Waters 717 autosampler. A multi-angle laser light scattering (MALLS) detector (Wyatt EOS) was coupled online with a differential refractometer Wyatt Optilab T-rEX $(\lambda=658 \mathrm{~nm}$ ). The separation was carried out on two columns (PL aquagel OH mixed M 8 micro and PL aquagel $\mathrm{OH}$ mixed $\mathrm{H} 8$ micro). Elution was performed at $22{ }^{\circ} \mathrm{C}\left(0.5 \mathrm{~mL} \mathrm{~min}^{-1}\right)$ using an aqueous buffer $\left(\mathrm{NaNO}_{3} 0.1 \mathrm{M}, \mathrm{Na}-\mathrm{EDTA} 0.01 \mathrm{M}, \mathrm{NaN}_{3} 0.03 \% \mathrm{w} / \mathrm{v}\right)$ after filtration on a $0.1 \mu \mathrm{m}$ pore-size membrane. The samples were prepared at a concentration of $4 \mathrm{mg} \mathrm{mL}^{-1}$ and filtered through a $0.45 \mu \mathrm{m}$ pore-size membrane prior to injection. The following $d n / d c$ values were used: $(d n / d c)_{\text {mannuronan }}=0.163$; $(\mathrm{d} n / \mathrm{d} c)_{\text {guluronan }}=0.163 ;(\mathrm{d} n / \mathrm{d} c)_{\text {NAM }}=0.172$. For the copolymers: $(\mathrm{d} n / \mathrm{d} c)_{\text {poly }(1-c o-2)}=\mathrm{w}_{1}(\mathrm{~d} n / \mathrm{d} c)_{1}+\mathrm{w}_{2}(\mathrm{~d} n / \mathrm{d} c)_{2}$ where $w_{1}$ et $w_{2}$ are weight fractions of monomers 1 (NAM) and 2 (glycuronan macromonomer).

For the copolymers containing glycuronan and PS segments, SEC measurements were performed in DMF (SEC-DMF) on an EcoSEC semi-micro GPC system from Tosoh equipped with a dual flow refractive index detector and a UV detector. The samples were analyzed in DMF (with $\mathrm{LiBr}$ at $0.01 \mathrm{~mol} \mathrm{~L}^{-1}$ ) at $50{ }^{\circ} \mathrm{C}$ using a flow rate of $1 \mathrm{~mL} \mathrm{~min}{ }^{-1}$. All polymers were injected at a concentration of $3 \mathrm{mg} \mathrm{mL}^{-1}$ in DMF, after 
filtration through a $0.45 \mu \mathrm{m}$ pore-size membrane. Separation was performed with 3 PSS GRAM columns ( $7 \mu \mathrm{m}, 300 \times 7.5 \mathrm{~mm}) \cdot M_{\mathrm{n}}$ and $\Theta$ were derived from the RI signal by a calibration curve based on polystyrene standards. WinGPC Unity software was used for data collection and calculation.

The latexes (diluted solution deposited on a carbon/formvar-coated copper grid and allowed to evaporate) were observed by transmission electron microscopy (TEM) with a Philips CM120 microscope operating at an accelerating voltage of $80 \mathrm{kV}$ (Centre Technologique des Microstructures, platform of the Université Claude Bernard, Lyon 1, Villeurbanne, France). The number- and mass-average particle diameter $\left(D_{n}\right.$ and $D_{w}$, respectively) as well as the particle-diameter dispersity $\left(D_{w} / D_{n}\right)$ were determined using AnalySIS software (Soft Imaging SysteM). A minimum of 150 objects was counted for each latex batch.

\section{Results and discussion}

In the first phase, the RAFT homopolymerization of NAM in water and the chain extension of the resulting macromolecules with styrene in emulsion polymerization were studied. In particular, the impact of the molar mass of PNAM and of the targeted degree of polymerization $\left(X_{n, t a r g e t}\right)$ of the PS block on (i) the degree of control of the block copolymer obtained, (ii) the colloidal stability and (iii) the morphology of the nano-objects was investigated. As such, this in one of the very few studies on PISA systems involving non-charged hydrophilic macroRAFT in emulsion. ${ }^{[20,61-68]}$ In the following phase, glycuronan-decorated nanoparticles were targeted. The aqueous RAFT copolymerization of glycuronan (i.e. mannuronan or guluronan) macromonomers with NAM was first investigated in order to obtain well-defined poly(NAMg-glycuronan) macroRAFT agents. NAM was chosen as the main constitutive unit of these hydrophilic chains since the use of acrylic acid (AA) or methacrylic acid (MAA) as co-monomers, although well characterized in our previous studies, ${ }^{[24,25,69]}$ was precluded by the insolubility of $(1 \rightarrow 4)$ - $\beta$-D-mannuronan and $(1 \rightarrow 4)$ - $\alpha$-L-guluronan at low $\mathrm{pH}^{\left[{ }^{[70]}\right.}$ Finally, these macroRAFT agents were used in a one-pot PISA process leading to oligosaccharide-decorated PS nanoparticles.

\section{PISA using PNAM as hydrophilic macroRAFT agent.}

Synthesis of PNAM macroRAFT agent. The RAFT polymerization of NAM has already been reported in the literature. ${ }^{[71-80]}$ In most cases, the polymerization was carried out in dioxane in the presence of different types of RAFT agent. Only two papers reported the synthesis of PNAM in aqueous solution. ${ }^{800,}$ ${ }^{81]}$ Nonetheless, Gody et al. ${ }^{[81]}$ had to add dioxane (20 vol\%) to solubilize the RAFT agent. Albertin et al. ${ }^{[80]}$ 
carried out a detailed study on the polymerization of NAM in $D_{2} \mathrm{O}$ with only $4 \% \mathrm{v} / \mathrm{v}$ of DMSO- $\mathrm{d}_{6}$ and in the presence of $S, S^{\prime}$-bis(2-propanoic acid) trithiocarbonate and ACPA as the RAFT agent and initiator, respectively. Good control over the molar mass of the obtained polymers and dispersity indices lower than 1.2 were achieved.

In our previous works, ${ }^{[23-25]}$ it was shown that the polymerization of hydrophilic monomers such as AA and MAA could be successfully performed in pure water in the presence of CTPPA and ACPA, although CTPPA was not highly soluble in water. Similarly, NAM was recently successfully polymerized by RAFT for the first time in pure water. [82] In this study CTPPA and ACPA were dissolved in NAM first, and water was then added. The resulting mixture was not perfectly homogeneous but became however quickly limpid once the polymerization started. The same protocol was followed here. In the first experiment, PNAM with a number-average molar mass $\left(M_{\mathrm{n}}\right)$ of $4000 \mathrm{~g} \mathrm{~mol}^{-1}$ was targeted (PNAM1, Figure 1). The polymerization was fast and quantitative conversion was reached in less than 2 hours after an initialization period of $45 \mathrm{~min}$ (Figure 1a). The narrow molar mass distributions and the linear evolution of the molar masses versus conversion indicated a good control of the polymerization (Figure $1 \mathrm{~b}$ and $\mathrm{c}$ ). The experimental molar masses were lower than expected due to the use of PS calibration for SEC analysis which is not well suited for the characterization of PNAM. ${ }^{[72]}$ MALDI-ToF mass spectrometry analyses of the final polymer however confirmed that the obtained molar mass was in good agreement $\left(M_{n}=4180\right.$ $\mathrm{g} \mathrm{mol}^{-1}, D=1.04$ ) with the expected value (Figure S1 in Supporting Information). Well-defined PNAM chains were thus produced in pure water with quantitative conversion. The same protocol was employed to synthesize different PNAM macroRAFT agents with theoretical number-average molar mass $\left(M_{n, t h}\right)$ of $4000 \mathrm{~g} \mathrm{~mol}^{-1}$ (PNAM1 to PNAM3), $2000 \mathrm{~g} \mathrm{~mol}^{-1}$ (PNAM4) and $8000 \mathrm{~g} \mathrm{~mol}^{-1}$ (PNAM5). SEC analysis (THF, PS calibration) of the resulting polymers gave the following results: PNAM1 $\left(M_{\mathrm{n}}=2410 \mathrm{~g} \mathrm{~mol}^{-1} / \oplus=1.10\right)$, PNAM2 $\left(M_{\mathrm{n}}=2460 \mathrm{~g} \mathrm{~mol}^{-1} / \oplus=1.05\right)$, PNAM3 $\left(M_{\mathrm{n}}=2470 \mathrm{~g} \mathrm{~mol}^{-1} / \oplus=1.06\right)$, PNAM4 $\left(M_{\mathrm{n}}=1235 \mathrm{~g} \mathrm{~mol}^{-1} /\right.$ $Ð=1.16)$ and PNAM5 $\left(M_{\mathrm{n}}=5060 \mathrm{~g} \mathrm{~mol}^{-1} / \oslash=1.07\right)$. All these samples were directly used for styrene emulsion polymerization without prior isolation (Table 2).

PISA mediated by PNAM macroRAFT agents for the polymerization of styrene. A first series of experiments were performed with PNAM macroRAFT agents with $M_{\mathrm{n}, \text { th }}$ of $4000 \mathrm{~g} \mathrm{~mol}^{-1}$. Considering the excellent control exhibited by the RAFT polymerization of NAM, the quantitative monomer conversion, and the results of MALDI-ToF analyses, the targeted molar mass was taken as a close approximation of the true one and used for stoichiometric calculations. The same amount of styrene was used for all experiments in combination with different concentrations of PNAM macroRAFT, thus targeting various degrees of polymerization for the PS block $\left(150<X_{n, \text { target }}<1600\right.$, Latex A1 to Latex A6, Table 2$)$. In all 
cases, after an induction period of 1 hour fast polymerizations were observed and full conversion was reached in ca. 2 hours (Figure 2a). As previously reported for PISA systems using PAA ${ }^{[24]}$ and PMAA ${ }^{[25]}$ macroRAFT agents, the induction period corresponds to the time required for the hydrophilic chains to add enough styrene units to induce the self-assembly of the resulting amphiphilic macromolecules.

Table 2: Emulsion polymerization of styrene using PNAM macroRAFT agents

\begin{tabular}{|c|c|c|c|c|c|c|c|c|c|}
\hline \multirow{2}{*}{ Expt. ${ }^{a}$} & \multicolumn{2}{|c|}{ PNAM } & \multirow{2}{*}{$X_{n, \text { target }}$} & \multirow{2}{*}{$\begin{array}{c}\text { Conv }^{b} \\
(\%)\end{array}$} & \multirow{2}{*}{$\begin{array}{c}M_{\mathrm{n}, \mathrm{th}} \\
\left(\mathrm{g} \mathrm{mol}^{-1}\right)\end{array}$} & \multirow{2}{*}{$\begin{array}{c}M_{\mathrm{n}}^{\mathrm{c}} \\
\left(\mathrm{g} \mathrm{mol}^{-1}\right)\end{array}$} & \multirow{2}{*}{$\boldsymbol{\theta}^{\mathrm{c}}$} & \multirow{2}{*}{$\begin{array}{l}D_{n}{ }^{d} \\
(n m)\end{array}$} & \multirow{2}{*}{$D_{\mathrm{w}} / D_{\mathrm{n}}{ }^{\mathrm{d}}$} \\
\hline & Batch name & $M_{\mathrm{n}, \mathrm{th}}$ & & & & & & & \\
\hline Latex A1 & PNAM1 & \multirow{6}{*}{4000} & 150 & 100 & 19620 & 20700 & 1.22 & 41 & 1.05 \\
\hline Latex A2 & PNAM2 & & 200 & 100 & 24830 & 28900 & 1.15 & 45 & 1.02 \\
\hline Latex A3 & PNAM2 & & 400 & 100 & 45660 & 44800 & 1.22 & 48 & 1.03 \\
\hline Latex A4 & PNAM2 & & 800 & 99 & 87320 & 83700 & 1.29 & 57 & 1.03 \\
\hline Latex A5 & PNAM3 & & 1200 & 100 & 128980 & 127700 & 1.34 & 58 & 1.08 \\
\hline Latex A6 & PNAM3 & & 1600 & 95 & 170640 & 159100 & 1.43 & 59 & 1.09 \\
\hline Latex A7 & PNAM4 & 2000 & 400 & 100 & 43660 & 52900 & 1.24 & 48 & 1.05 \\
\hline Latex A8 & PNAM5 & 8000 & 400 & 100 & 49660 & 57600 & 1.29 & 56 & 1.03 \\
\hline
\end{tabular}

${ }^{a}$ All the experiments were performed at $\mathrm{T}=80^{\circ} \mathrm{C}$ with $[$ styrene $]=2.4 \mathrm{~mol} \mathrm{~L}^{-1}$ water, $\left[\mathrm{NaHCO}_{3}\right] /[\mathrm{ACPA}]=3.5 ;[\mathrm{PNAM}] /[\mathrm{ACPA}]=5 ; \mathrm{t}$ $=2 \mathrm{~h} .{ }^{\mathrm{b}}$ The conversion was determined by gravimetry. ${ }^{\mathrm{c}} M_{n}$ and $\Theta$ were obtained by SEC-THF using PS calibration. ${ }^{\mathrm{d}}$ Particle diameter and dispersities were obtained by TEM.

Very good control over the molar mass was obtained for targeted $X_{n}\left(X_{n, \text { target }}\right)$ values as high as 1600 . This was shown by the rapid and quantitative consumption of the initial macroRAFT agent (Figure 3 ), the narrow molar mass distributions and the linear increase of molar masses with conversion (Figure 2b). The obtained latexes were very stable, and small and isometric nanoparticles $\left(D_{\mathrm{n}}<60 \mathrm{~nm}, D_{\mathrm{w}} / D_{\mathrm{n}} \leq 1.09\right)$ were formed in each case (Table 2 and Figure 3). As expected, particle diameters increased slightly with the increase of the PS block molar mass. Likewise, the size distribution became slightly broader for $X_{n, \text { target }}>$ 800 but remained consistent with the exclusive formation of PNAM- $b$-PS amphiphilic block copolymer particles according to a PISA process.
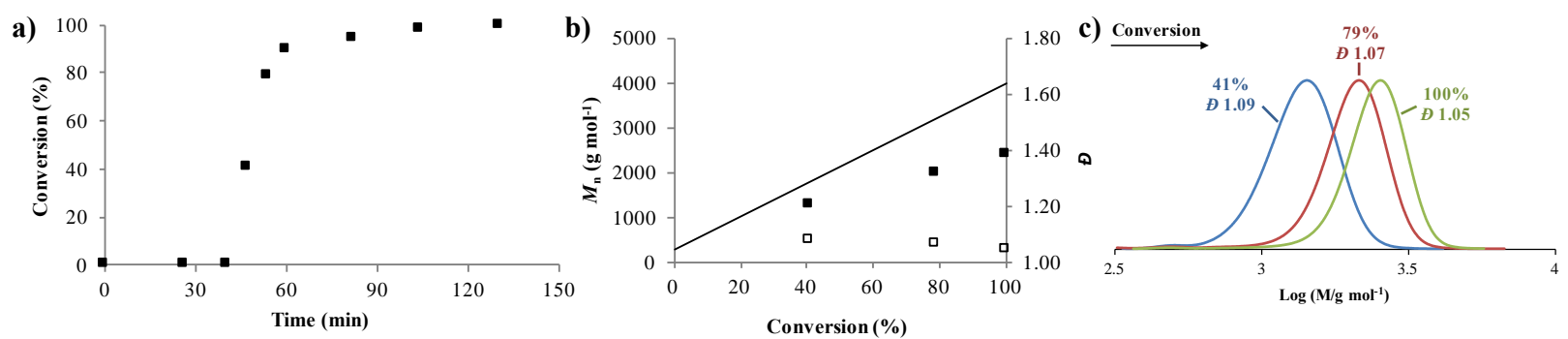

Figure 1: Synthesis of PNAM1 by RAFT polymerization of NAM in water at $80^{\circ} \mathrm{C}$ in the presence of CTPPA and ACPA. $[N A M]=1 \mathrm{~mol} \mathrm{~L}^{-1},[\mathrm{NAM}] /[\mathrm{CTPPA}]=26,[\mathrm{CTPPA}] /[\mathrm{ACPA}]=10 . \mathrm{M}_{\mathrm{n}, \mathrm{th}}=4000 \mathrm{~g} \mathrm{~mol}^{-1}$. Evolution of (a) the conversion versus time (b) $M_{\mathrm{n}}$ and $\emptyset$ versus conversion $\left(M_{\mathrm{n}}\right.$ et $\emptyset$ were obtained by SEC in THF with PS calibration) (c) the size exclusion chromatograms versus conversion. 

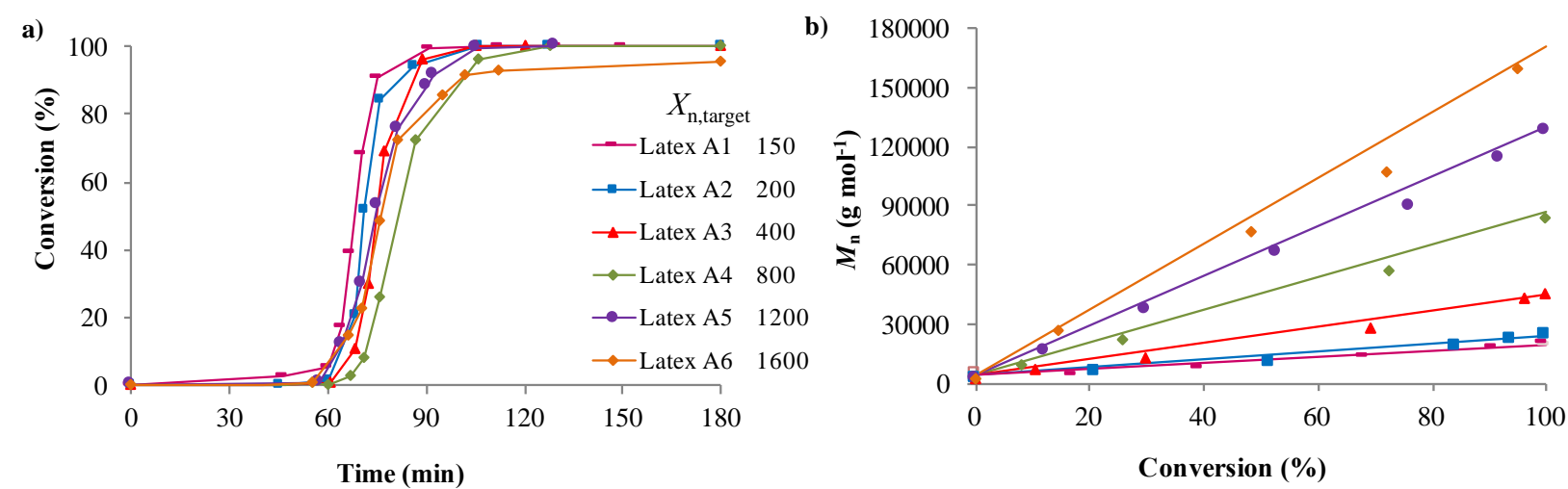

Figure 2: RAFT emulsion polymerization of styrene performed with PNAM macroRAFT agents (4000 $\mathrm{g} \mathrm{mol}^{-1}$, PNAM1PNAM3) targeting different $X_{n}$ for the PS block (Table 2). Evolution of (a) monomer conversion versus time and (b) number-average molar mass $M_{n}$ versus conversion. The straight line corresponds to the theoretical evolution of molar masses with conversion.

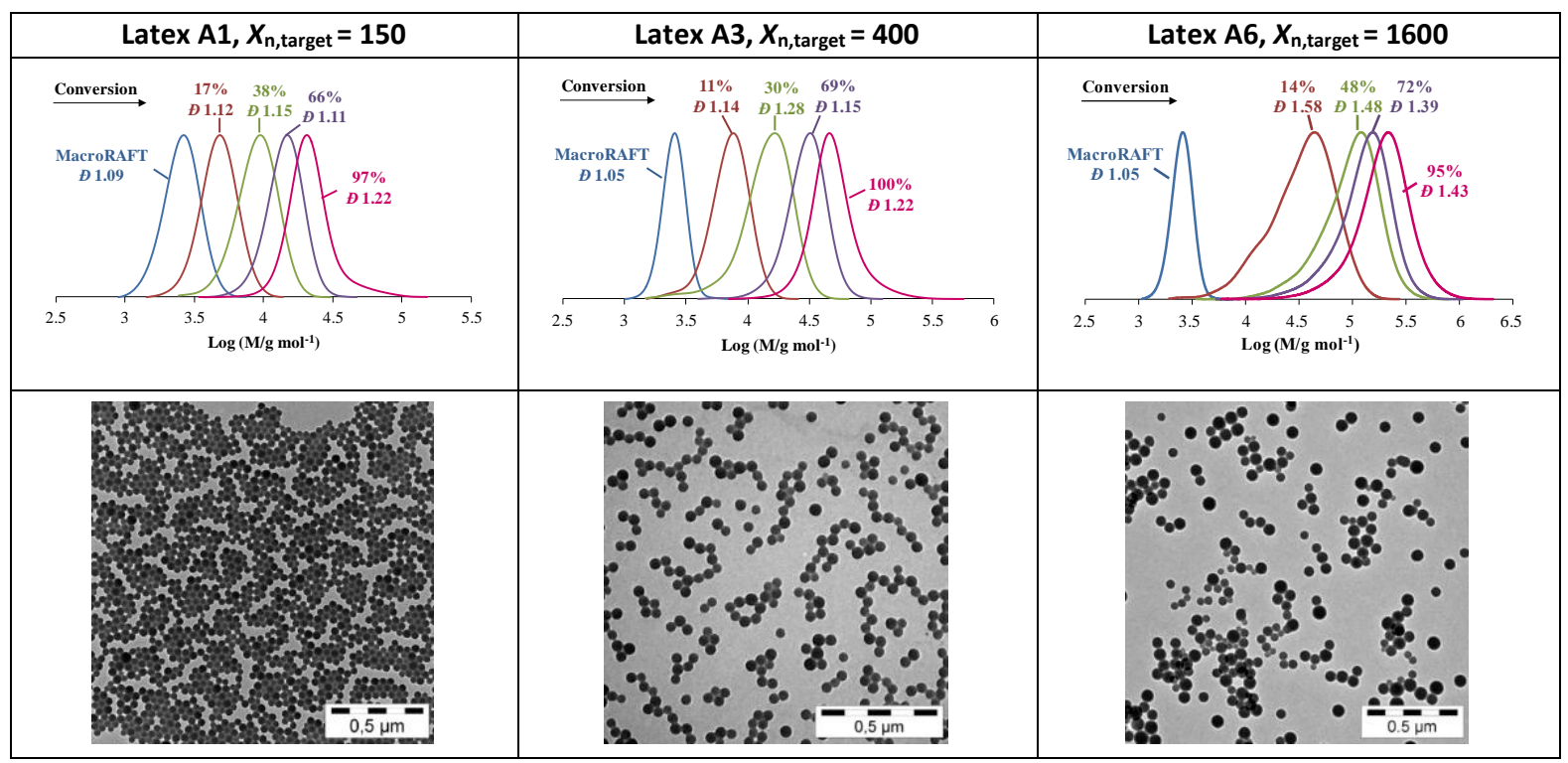

Figure 3: Evolution of the size exclusion chromatograms versus conversion and TEM images of the final latexes for the RAFT emulsion polymerizations of styrene carried out with PNAM macroRAFT agents $\left(M_{\mathrm{n}, \mathrm{th}}=4000 \mathrm{~g} \mathrm{~mol}{ }^{-1}\right.$, PNAM1 - PNAM3) for PS block of different $X_{n, \text { target }}$ (Table 2 ).

The influence of the molar mass of the macroRAFT agent on nanoparticle synthesis was investigated in a second series of experiments. Two additional PNAM macroRAFT agents (PNAM4, $M_{\mathrm{n}, \mathrm{th}}=2000 \mathrm{~g} \mathrm{~mol}^{-1}$ and PNAM5, $M_{\mathrm{n}, \mathrm{th}}=8000 \mathrm{~g} \mathrm{~mol}^{-1}$ ) were used at the same concentration for the RAFT emulsion polymerization of styrene (Latex A7 and Latex A8, Table 2). The targeted $X_{n}$ for the PS block was fixed to 400 . Polymerizations were very fast (Figure 4a) and the induction period was significantly longer for the shortest macroRAFT agent (Latex A7). This behaviour has already been observed for the emulsion 
polymerization of styrene in the presence of PMAA-CTPPA. ${ }^{[25]}$ As mentioned above, the induction period corresponds to the time needed to add enough styrene units as to induce self-assembly of the resulting block copolymer. Decreasing the molar mass of the PNAM macroRAFT agent decreases its polymeric character and may increase its hydrophilicity. As a result, a longer hydrophobic PS block will be needed to induce self-assembly, which will take longer to form. For the three experiments a very good control of the polymerization was obtained with low molar mass dispersities (Figure 4b). Again, small and isometric spherical particles were invariably observed (Figure 5). With macroRAFT agents of $M_{n, t h} 2000$ and $4000 \mathrm{~g}$ $\mathrm{mol}^{-1}$, similar particle sizes were obtained $(48 \mathrm{~nm})$ whereas the use of a macroRAFT of higher molar mass led to the production of bigger particles $(56 \mathrm{~nm})$. This could be attributed to very limited coalescence in the latter case.
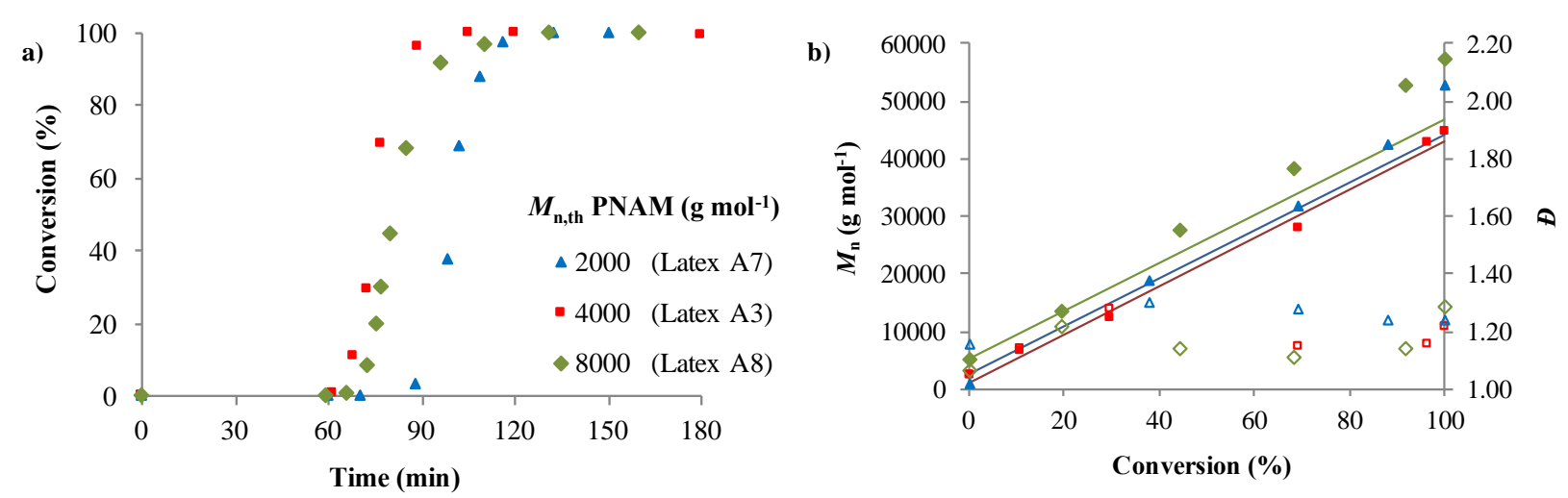

Figure 4: RAFT emulsion polymerization of styrene $\left(X_{n, \text { target }}=400\right)$ performed with PNAM macroRAFT agents of different molar mass (Table 2). Evolution of (a) monomer conversion versus time and (b) number-average molar mass $M_{n}$ versus conversion. The straight line corresponds to the theoretical evolution of molar mass with conversion.

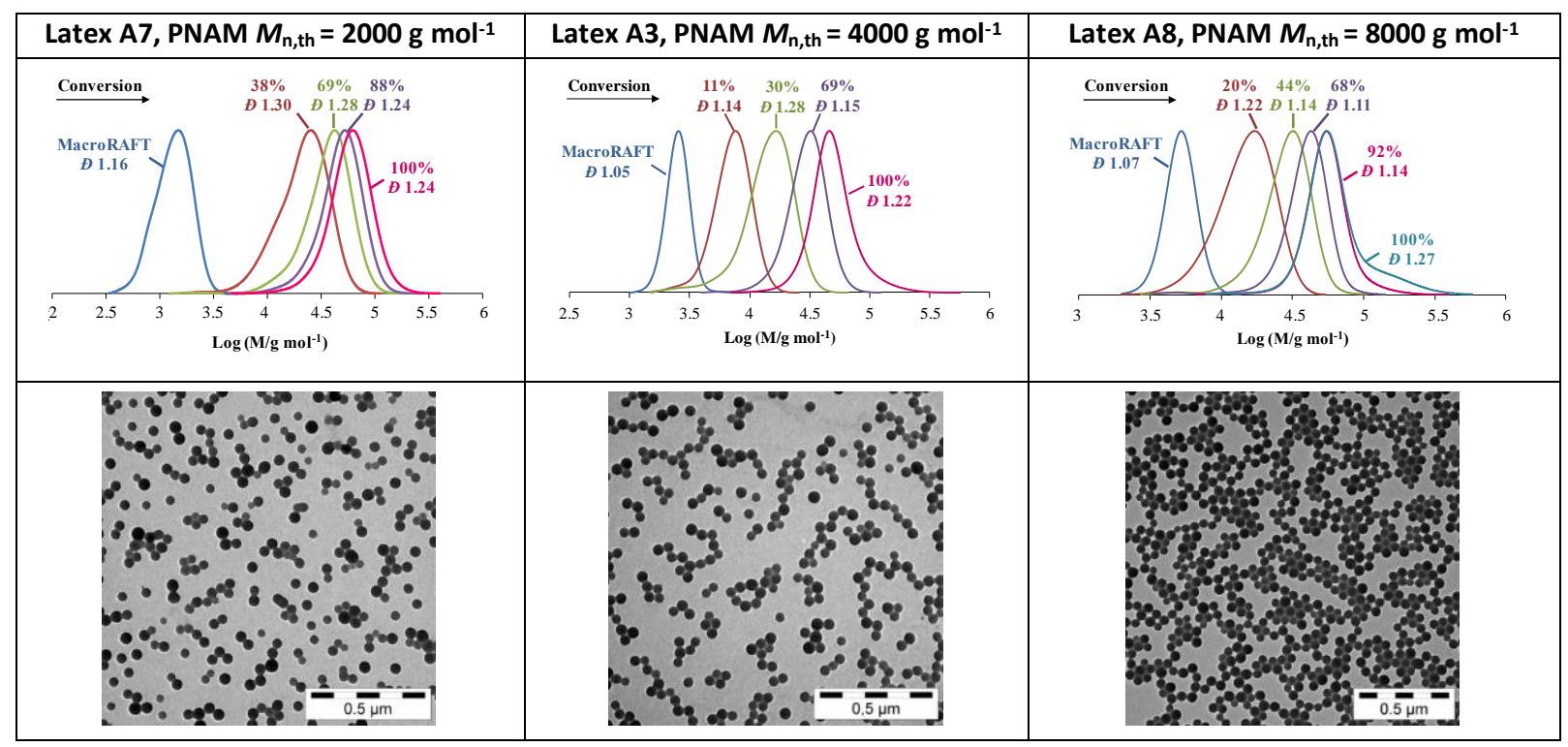


Figure 5: Evolution of the size exclusion chromatograms versus conversion and TEM images of the final latexes for the RAFT emulsion polymerizations of styrene $\left(X_{n, \text { target }}=400\right)$ carried out with PNAM macroRAFT agents of different molar mass (See Table 2 for details).

Based on these results, hydrophilic PNAM macroRAFT agents appear to be excellent candidates for the production by PISA of self-stabilized spherical PS nanoparticles composed of well-defined amphiphilic block copolymers of different molar masses. It is however surprising that spherical particles were invariably obtained, especially in the case of Latex A6 incorporating highly asymmetric $\mathrm{PNAM}_{26}-b-\mathrm{PS}_{1600}$ amphiphilic block copolymer chains. In general, the copolymer composition is one of the main parameters directing the self-assembly of amphiphilic block copolymers in water and its tuning enables the formation of different morphologies. Recently, Armes and coworkers have also reported the exclusive formation of spheres when studying the synthesis of amphiphilic block copolymer particles composed of a neutral hydrophilic poly(glycerol monomethacrylate) segment and a hydrophobic poly(benzyl methacrylate) segment by PISA in water. ${ }^{[61]}$

Hence, although the effect of PNAM macroRAFT agents remains intriguing, the overall process represents a robust PISA system for which it was anticipated that slight modifications, such as the introduction of a few negatively charged graft chains in the PNAM block, should allow the formation of the targeted spherical particles decorated with mannuronan or guluronan moieties.

\section{PISA mediated by glycuronan-based macroRAFT agents for the polymerization of styrene.}

\section{Synthesis of glycuronan-based macroRAFT agents in water.}

RAFT copolymerization of NAM with methacrylate macromonomers in water. The oligosaccharides used in this study have contour lengths $(c a .8 .7 \mathrm{~nm})^{[83,84]}$ that are smaller than the intrinsic persistence length of the corresponding high molar mass polysaccharides $\left(I_{p, \operatorname{ManAx}} \cong 14.5 \mathrm{~nm}, I_{\mathrm{p}, \text { GulAx}} \cong 14.5 \mathrm{~nm}\right) .{ }^{[85]}$ In solution they will then behave as semi-flexible rods and their stiffness may affect the stabilizing capability of the respective macroRAFT agents. The ion-binding and biological properties of ( $1 \rightarrow 4)-\beta$-D-mannuronan and $(1 \rightarrow 4)$ - $\alpha$-L-guluronan are different though, and the ability to decorate the target particles with either glycuronans would be advantageous.

Two types of methacrylate macromonomers were used: mannuronan methacrylate ( $\left.M a n A_{17} M A\right)$ and guluronan methacrylate $\left(\mathrm{Gul}_{20} \mathrm{MA}\right)$. In previous studies ${ }^{[59]}$ it was found that these type of methacrylate macromonomers copolymerize with 2-hydroxyethyl methacrylamide in water by free radical or RAFT polymerization. Here, their RAFT copolymerization with NAM was performed under conditions similar to those used for NAM homopolymerization. 
Table 3: Features of glycuronan-based macroRAFT agents synthesized in this study

\begin{tabular}{|c|c|c|c|c|c|c|c|c|}
\hline \multirow[t]{2}{*}{ Exp. $^{\mathrm{a}}$} & \multicolumn{3}{|c|}{ Macromonomer } & \multicolumn{5}{|c|}{ MacroRAFT } \\
\hline & Type $^{b}$ & $\begin{array}{c}M_{\mathrm{n}} \\
\left(\mathrm{g} \mathrm{mol}^{-1}\right)\end{array}$ & $\begin{array}{c}Q \\
(w t \%)^{c}\end{array}$ & $\begin{array}{l}\text { NAM/macrod } \\
\text { (mol\%) }\end{array}$ & $\begin{array}{c}\text { [NAM] } \\
\text { (mol L-1 water) }\end{array}$ & $\begin{array}{c}\text { [NAM+macro]/[RAFT] } \\
\text { (mol L-1 water) }\end{array}$ & $\begin{array}{c}M_{\mathrm{n}, \mathrm{th}} \\
\left(\mathrm{g} \mathrm{mol}^{-1}\right)\end{array}$ & $\begin{array}{c}\text { Glycuronan } \\
\text { (wt\%) }\end{array}$ \\
\hline M1 & $\mathrm{ManA}_{17} \mathrm{MA}$ & 3800 & 62 & $96 / 4$ & 0.84 & 27 & 7700 & 55 \\
\hline G1 & $\mathrm{GulA}_{20} \mathrm{MA}$ & 4210 & 62 & $96 / 4$ & 0.67 & 26 & 8020 & 56 \\
\hline
\end{tabular}

a Both experiments were performed at $\mathrm{T}=80{ }^{\circ} \mathrm{C}$ with $[\mathrm{CTPPA}] /[\mathrm{ACPA}]=10$. ${ }^{\mathrm{b}} \mathrm{ManA}_{17}$ and GulA $\mathrm{A}_{20}$ represent $(1 \rightarrow 4)-\beta-\mathrm{D}$ mannuronan with 17 number-average repeating units and $(1 \rightarrow 4)$ - $\alpha$-L-guluronan with 20 number-average repeating units, respectively; MA stands for methacrylate. ' $Q$ is the degree of functionalization of the macromonomer, i.e. the mass fraction of oligosaccharides bearing a polymerizable methacrylate function. ${ }^{d} \mathrm{NAM} /$ macromonomer molar ratio in the feed.

Initially, a mixture of ManA ${ }_{17} \mathrm{MA}$ and NAM (molar ratio 96/4, ca. 1-2 mannuronan grafts per chain) was copolymerized by RAFT (experiment M1, Table 3). Complete monomer conversion was reached in 100 min, but after 50 min all ManA ${ }_{17}$ MA had been consumed (Figure $6 a$ ) whereas only $78 \%$ of NAM had polymerized. This difference in reactivity between methacrylate and acrylamide monomers was expected ${ }^{[86]}$ and leads to a gradient in composition of polymer chains. As a result mannuronan grafts will be found towards the $\alpha$-end whereas only NAM units will be found towards the $\omega$-end capped by the trithioylpropyl group of the RAFT agent. Furthermore, since glycuronan macromonomers do not homopolymerize in solution, ${ }^{[58]}$ graft chains will be probably isolated along the copolymer main chain. The SEC analysis of samples taken at different times was performed to assess the evolution of molar mass distributions with conversion (Figure 6b). This confirmed that a higher molar mass population was formed and shifted towards lower elution volumes with reaction time. Unfortunately, unreacted oligomannuronan chains from macromonomer synthesis gave rise to a peak at $15.4 \mathrm{~mL}$ partially superimposed to that of the newly formed chains that prevented the determination of molar mass distributions.

When a similar experiment was performed with guluronan macromonomer GulA ${ }_{20} \mathrm{MA}$ ( $\mathrm{G} 1$ in Table 3 and Figure $6 c-d)$, comparable results were obtained. The polymerization was complete in $100 \mathrm{~min}$ and the macromonomer was incorporated faster, leading to gradient copolymers. As for the previous experiment, the presence of unreacted guluronan chains from macromonomer synthesis prevented the determination of molar mass distributions. Nonetheless SEC traces showed that a higher molar mass population was formed and shifted towards lower elution volumes with the proceeding of reaction. The formation and livingness of the $P\left(N A M-c o-M a n A_{17} M A\right)$ and $P\left(N A M-c o-G u l A_{20} M A\right)$ chains will actually be 
demonstrated a posteriori (in the following section), when performing the emulsion polymerization of styrene.

a)

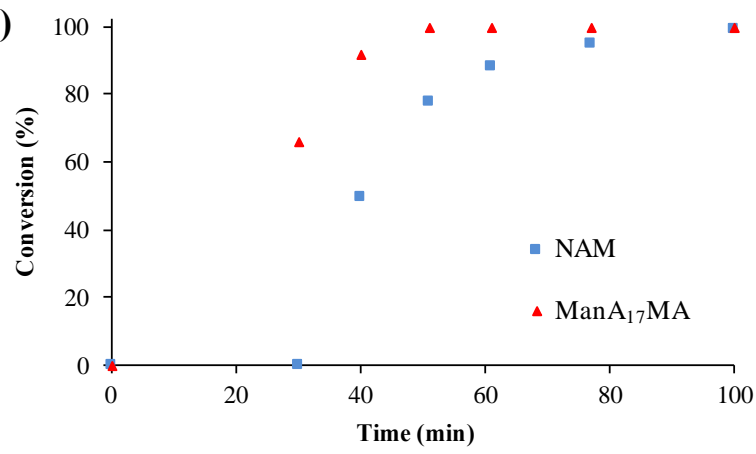

c)

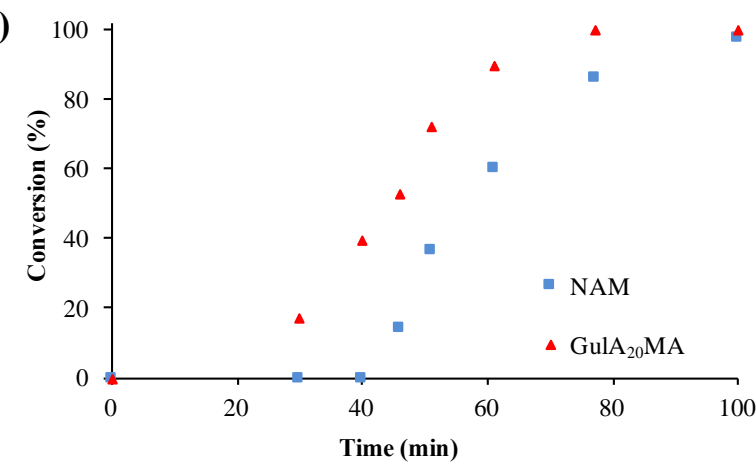

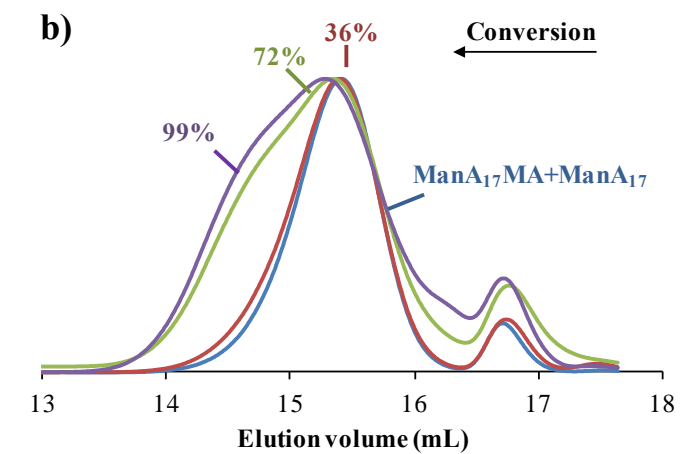

d)

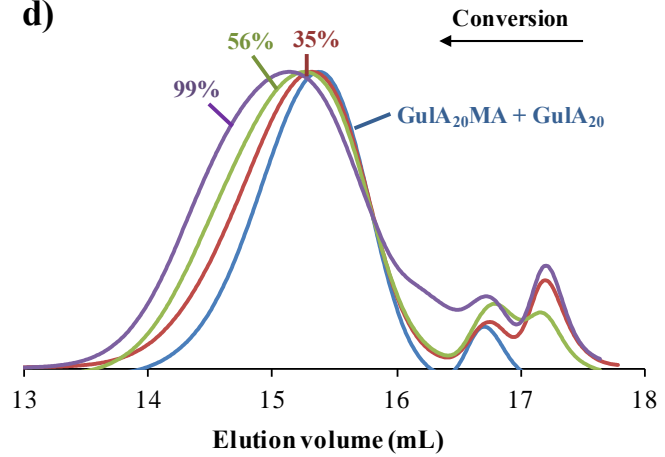

Figure 6: Evolution of the conversion versus time $(a-c)$ and of the aqueous size exclusion chromatograms versus conversion (ASEC) (b-d) for the synthesis of glycuronan-based macroRAFT. (a-b) Synthesis of P(NAM-co-ManA $\left.{ }_{17} M A\right)$ (M1). (c-d) Synthesis of $\mathrm{P}\left(\mathrm{NAM}-\mathrm{co}-\mathrm{GulA}_{20} \mathrm{MA}\right)(\mathrm{G} 1)$. See Table 3 for detailed experimental conditions. Note that the small peaks at $\sim 16.7 \mathrm{~mL}$ are due to very low molar mass species from the reaction mixture and from the eluent, and should be disregarded.

\section{PISA mediated by glycuronan-based macroRAFT agents for the polymerization of styrene.}

The mannuronan- and guluronan-based macroRAFTs described in the previous section were used to control the emulsion polymerizations of styrene in a one-pot process (Table 4).

Table 4: Emulsion polymerizations of styrene using glycuronan-based macroRAFT agents.

\begin{tabular}{|c|c|c|c|c|c|c|c|}
\hline Exp. & MacroRAFT & $\begin{array}{c}\text { Conv } \\
(\%)^{\mathbf{b}}\end{array}$ & $\begin{array}{c}\text { Time } \\
\text { (h) }\end{array}$ & $\begin{array}{c}\boldsymbol{M}_{\mathrm{n}, \mathrm{th}} \\
\left(\mathbf{g ~ m o l}^{-1}\right)\end{array}$ & $\begin{array}{c}\boldsymbol{M}_{\mathrm{n}}{ }^{\mathrm{c}} \\
\left(\mathbf{g ~ m o l}^{-1}\right)\end{array}$ & $\boldsymbol{\Xi}^{\mathrm{c}}$ & $\begin{array}{c}\boldsymbol{D}_{\mathrm{n}}(\mathrm{nm})^{\mathrm{d}} \\
\left(\boldsymbol{D}_{\mathrm{w}} / \boldsymbol{D}_{\mathrm{n}}{ }^{\mathrm{d}}\right)\end{array}$ \\
\hline Latex B1 & $\mathrm{M} 1$ & 100 & 3 & 49360 & 43600 & 1.56 & $27(1.12)$ \\
\hline Latex B2 & $\mathrm{G} 1$ & 100 & 3 & 49460 & 45700 & 1.50 & $31(1.07)$ \\
\hline
\end{tabular}

a Both experiments were performed at $T=80^{\circ} \mathrm{C}$ with [styrene $]_{0}=2.4 \mathrm{~mol} \mathrm{~L}-1$ water; $X_{\mathrm{n}, \text { target }}=400 ;\left[\mathrm{NaHCO}_{3}\right] /[\mathrm{ACPA}]=3.5$; $\left[\right.$ MacroRAFT] $/[\mathrm{ACPA}]=5 ; \mathrm{pH} \approx 6-6.5 .{ }^{\mathrm{b}}$ Conversions were determined by gravimetry. ${ }^{\mathrm{c}} M_{\mathrm{n}}$ and $\emptyset$ were obtained by SEC-DMF using PS calibration. ${ }^{d}$ Particle diameters and dispersities were obtained by TEM.

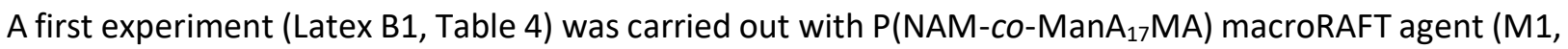
Table 3) under the same conditions previously used for Latex A3 ([Sty]/[macroRAFT] = 400, Table 2). 
Assuming a complete conversion of the starting CTPPA into the macroRAFT agent, and since it is a onepot process, the concentration of macroRAFT was considered to be identical to [CTPPA] $]_{0}$ Styrene polymerization was fast and, after an induction period of $1 \mathrm{~h} 20$, quantitative conversion was achieved in less than 2 hours (Figure 7a). The kinetic profile is similar to that previously obtained with PNAM (Figure 2a) and the longer induction period can be ascribed to the more pronounced hydrophilic character of $\mathrm{P}\left(\mathrm{NAM}-\mathrm{co}-\mathrm{ManA}_{17} \mathrm{MA}\right)$ compared to PNAM. As shown in Figure $7 \mathrm{~b}$, a good control of the molar mass was obtained but the dispersity index was slightly higher ( $\theta \cong 1.6$, SEC-DMF) than in the case of PNAM- $b$-PS $(\Theta \leq 1.3, \mathrm{SEC}-\mathrm{THF})$. The good agreement between experimental and theoretical molar masses suggests that the consumption of the $\mathrm{P}\left(\mathrm{NAM}-\mathrm{Co}-\mathrm{ManA}_{17} \mathrm{MA}\right)$ macroRAFT agent was quasi-quantitative and confirms a posteriori that the RAFT copolymerization of NAM and ManA ${ }_{17}$ MA produced dormant chains as expected for a well-controlled process. It also indicates that the RAFT chain ends were not consumed in side reactions during the synthesis of the macroRAFT agent. The tail observed in the lower molar mass region of the distributions that contributes to their broadening is at least in part due to the nonfunctionalized mannuronan chains present in the reaction mixture (Figure 8). Besides, these results also indicate that the outcome of the first step (i.e. the synthesis of the macroRAFT) was not an ill-defined mixture of polymer chains (i.e. the targeted macroRAFT structure, PNAM oligomers or any other oligomer species), or we would not observe the rather clean chain extension observed when styrene was then polymerized in water (i.e. one population, with a dispersity around 1.5). Stable and small nanoparticles $\left(D_{\mathrm{n}}=27 \mathrm{~nm}\right)$ fairly homogeneous in size $\left(D_{\mathrm{w}} / D_{\mathrm{n}}=1.12\right)$ were observed by TEM (Figure 8). Their formation confirms that the synthesised $\mathrm{P}\left(\mathrm{NAM}-\mathrm{co}-\mathrm{ManA}_{17} \mathrm{MA}\right)-b$-PS amphiphilic block copolymers self-assembled in situ according to a PISA process and afforded mannuronan-decorated nanospheres.

The chemical structure, chain rigidity, chain extension and charge density of mannuronan and guluronan are the same ${ }^{[85]}$ and, all other parameters being equal, the nature of the glycuronan grafts in the macroRAFT agent is not expected to influence the formation and stabilization of PS nanoparticles by PISA. This assumption was verified by performing an experiment (Latex B2, Table 4) identical to Latex B1 in everything but the presence of GulA $_{20}$ graft chains, that replaced $\mathrm{ManA}_{17}$ ones, using $\mathrm{P}(\mathrm{NAM}-\mathrm{CO}-$ GulA $\left._{20} M A\right)$ macroRAFT agent (G1, Table 3). The final conversion, molar mass and mass dispersity were nearly identical in the two cases but a longer induction period was observed for Latex B2 (100 min) than for Latex $B 1$ (80 min), suggesting a higher hydrophilicity of P(NAM-co-GulA $\left.A_{20} M A\right)$ macroRAFT chains (see discussion in previous section on PNAM-stabilized latexes). Small spherical and fairly uniform particles were produced $\left(D_{\mathrm{n}}=31 \mathrm{~nm}, D_{\mathrm{w}} / D_{\mathrm{n}}=1.07\right)$ consistent with the PISA of P(NAM-co-GulA $\left.{ }_{20} \mathrm{MA}\right)-b$-PS amphiphilic block copolymers.

These two experiments confirm that the nature of the glycuronan featured by the hydrophilic macroRAFT agent $\left(\mathrm{ManA}_{17}\right.$ or $\mathrm{Gul}_{20}$ ) has little influence on the course of the polymerization, at least when the 
oligosaccharides are distant from the particle surface (cf. compositional gradient mentioned in previous section). In both cases, stable and spherical PS particles functionalized by glycuronan chains were obtained.

Finally, to rule out any interference from unfunctionalized glycuronan chains still present from macromonomer synthesis, two additional experiments were performed. In the first one, styrene was polymerized in the presence of a mannuronan macromonomer (with ManA $\mathrm{A}_{11} \mathrm{MA}$, see Table S1 in the Supporting Information). Monomer conversion was limited and the latex was unstable (data not shown). However, spherical particles with a diameter ranging between 85 and $330 \mathrm{~nm}$ were observed in TEM. In the second experiment, a PNAM macroRAFT agent was added to the previous formulation. Uniform spherical particles of $180 \mathrm{~nm}$ were formed (data not shown). The discrepancies in terms of colloidal features between these two experiments and that carried out with the macroRAFT agent clearly indicate that the mannuronan chains must be integrated in the hydrophilic block to play a significant role in the particle formation and stabilization. It is worth mentioning that unfunctionalized guluronan chains could be easily separated from the latex after the emulsion polymerization step by simple centrifugation (or dialysis) (but would remain a hard task before this step). In that respect the low purity of the glycuronan macromolecules - although of real concern for their efficient production - is not an impediment for the production of the targeted particles.
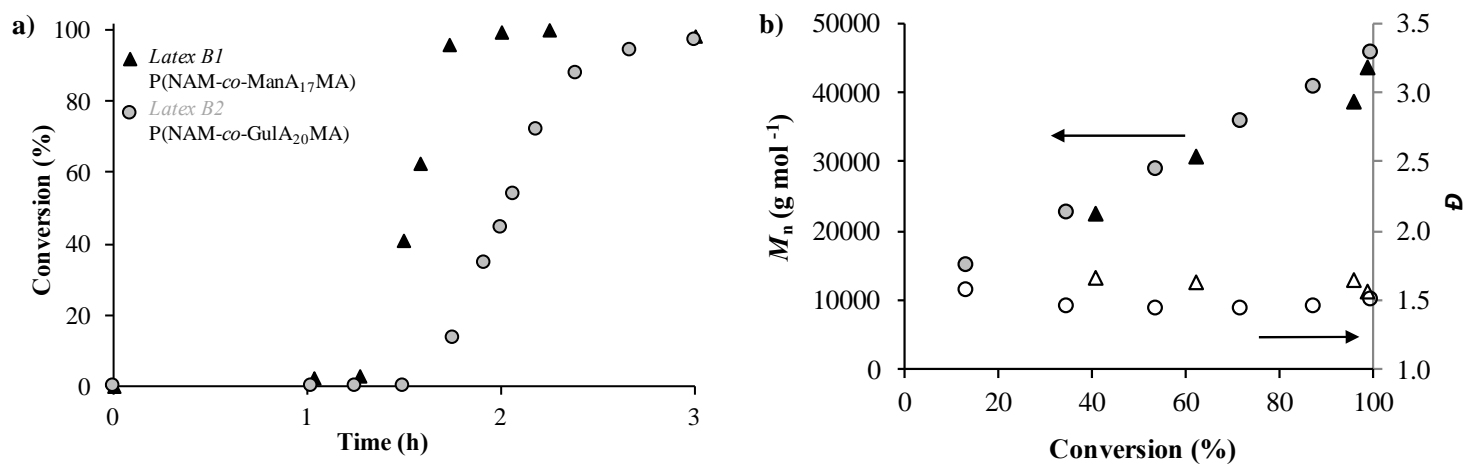

Figure 7: RAFT emulsion polymerizations of styrene performed with $P\left(N A M-c o-M a n A_{17} M A\right)$ and $P\left(N A M-c o-G u l A_{20} M A\right)$ macroRAFT agents (molar composition 96/4). Evolution of (a) monomer conversion versus time and (b) number-average molar mass $M_{\mathrm{n}}$ versus conversion. See Table 4 for detailed experimental conditions. 


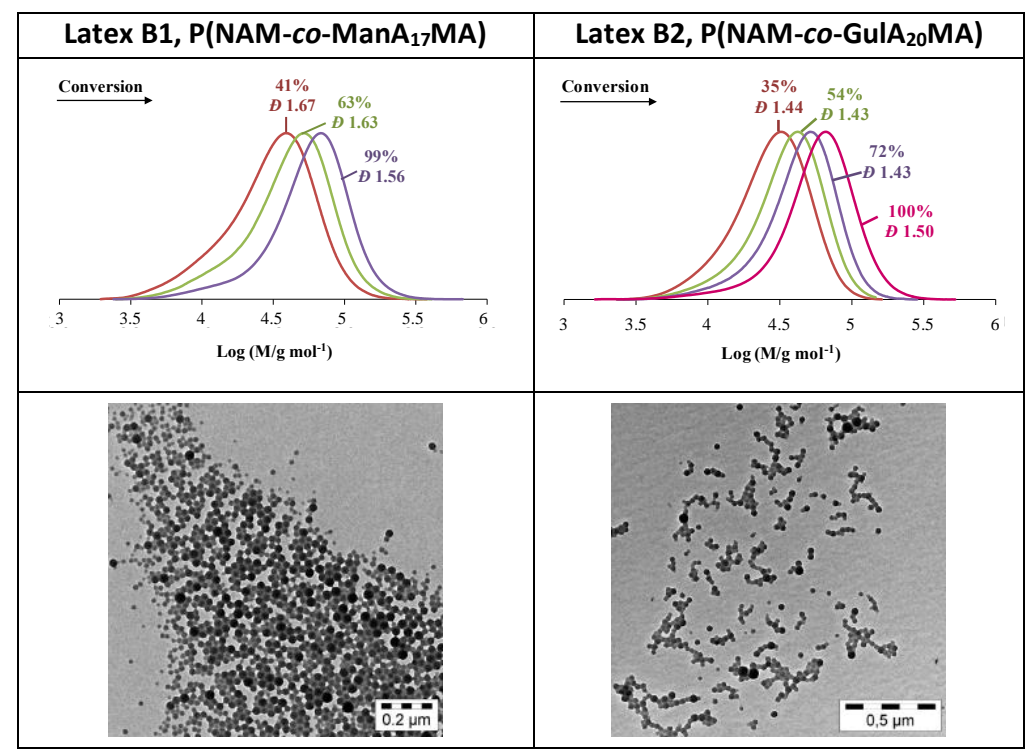

Figure 8: Evolution of the size exclusion chromatograms versus conversion and TEM images of the final latexes for the RAFT emulsion polymerizations of styrene carried out with $\mathrm{P}\left(\mathrm{NAM}-\mathrm{Co}-\mathrm{ManA}_{17} \mathrm{MA}\right)$ and $\mathrm{P}\left(\mathrm{NAM}-\mathrm{Co}-\mathrm{Gul} \mathrm{A}_{20} \mathrm{MA}\right)$ macroRAFT agents (molar composition 96/4).

The use of macroRAFT agents in which the molar mass of the glycuronan graft chains was halved (namely $P\left(N A M-c o-M a n A_{11} M A\right)$ and $\left.P\left(N A M-c o-G u l A_{11} M A\right)\right)$ led again to a good control of the emulsion polymerization step. However, a striking change in the morphology of the obtained objects was noticed: vesicular-like aggregates could be observed together with a small amount of spheres (Tables S1 and S2, and Figure S2, Supporting Information). As spheres were exclusively obtained with PNAM, P(NAM-coMan $\left.A_{17} M A\right)$ and $P\left(N A M-c o-G u l A_{20} M A\right)$, the observed sharp morphological transition was unexpected. It was indeed assumed that a macroRAFT with an anticipated intermediate hydrophilic character, i.e.

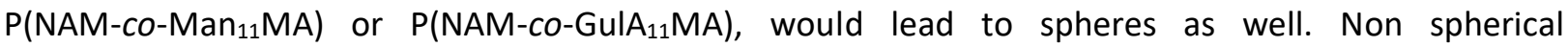
morphologies were also obtained when using a glycuronan-based macroRAFT in which the alginate moiety was randomly distributed along the PNAM backbone (obtained by the copolymerization of NAM and an acrylamide-type macromonomer $\mathrm{ManA}_{11} \mathrm{Am}$, see Tables S1, S2 and Figure S2, Supporting Information). Both the architecture of the macroRAFT, i.e. the positioning of the macromonomer side chains, and its intrinsic hydrophilicity (macroRAFT based on glycuronan acrylamides should be more hydrophilic than those based on glycuronan methacrylates) would thus impact the particle morphology. The main goal of this study being the synthesis of glycuronan decorated spherical nanoparticles by the PISA process, these morphological aspects, that would require the use of very well-defined structures to be tackled and explained, were not further investigated in the present paper. Indeed, an in-depth study from our group on the effect of the positioning of a hydrophilic macromonomer in the PNAM hydrophilic 
macroRAFT has recently been published ${ }^{[82]}$ and tries to further contribute to the understanding and the control of the self-assembly of amphiphilic block copolymers.

\section{Conclusions}

Poly( $N$-acryloylmorpholine) macroRAFT agents were first synthesized in water by RAFT. A thorough study of styrene polymerization by polymerization-induced self-assembly (PISA) using the obtained PNAM macroRAFT agents was then undertaken, showing the systematic formation of nanospheres $\left(D_{\mathrm{n}}<60 \mathrm{~nm}\right)$ whatever the molar mass of PNAM (from 2000 to $8000 \mathrm{~g} \mathrm{~mol}^{-1}$ ) or the polymerization degree targeted for the PS block (from 150 to 1600). Glycuronan macromonomers derived from alginates and carrying a methacrylate polymerizable function were then copolymerized with NAM by RAFT in water to produce hydrophilic macroRAFT agents carrying either $(1 \rightarrow 4)$ - $\beta$-D-mannuronan $\left(\mathrm{ManA}_{17}\right)$ or $(1 \rightarrow 4)$ - $\alpha$-L-guluronan $\left(G_{1} A_{20}\right)$ side chains. The latter were further used to polymerize styrene in water to obtain alginatedecorated nanoparticles. Stable latex particles composed of amphiphilic block copolymers were obtained in quantitative yield and short polymerization times according to a RAFT mediated PISA process. The targeted spherical nanoparticles $\left(D_{\mathrm{n}} \approx 30 \mathrm{~nm}\right)$ were obtained for both P(NAM-co-Man $\left.{ }_{17} \mathrm{MA}\right)$ and P(NAMco-Gul ${ }_{20} \mathrm{MA}$ ) macroRAFT agents, for which glycuronan side-chains were concentrated towards the $\alpha$-end of the hydrophilic block. By exploiting the ion-binding properties of $(1 \rightarrow 4)$ - $\alpha$-L-guluronan and other glycuronans, ${ }^{[42,87]}$ the approach depicted here could be used to produce film-forming latexes suitable for the fabrication of dust suppressing coatings for the response to a radiation dispersal accident: They would combine the properties of protective polymer films ${ }^{[88,89]}$ and those of a selective sorbent to increase efficiency of radionuclides fixation after nuclear accidents. ${ }^{\text {[90, 91] }}$

\section{Acknowledgements}

The financial support from the French National Agency for Research (ANR ALGIMAT 09-CP2D-02) and from the competitiveness cluster Axelera is acknowledged. The authors would like to thank Olivier Boyron and Pierre-Yves Dugas (C2P2, LCPP Team) for their help concerning SEC analyses and cryo-TEM, respectively. Agnes Crepet (IMP, Villeurbanne) is acknowledged for her help with aqueous SEC analyses.

\section{Appendix A. Supplementary data}


Supplementary data related to this article can be found at http://dx.doi.org/10.1016/j.polymer.xxxxx.

(MALDI-ToF analysis of PNAM 1; Synthesis of glycuronan-decorated particles using ManA ${ }_{11} M A-$, GulA $\mathrm{A}_{11} \mathrm{MA}$ - or ManA $\mathrm{A}_{11} \mathrm{Am}$-based macroRAFT agents)

\section{References}

1. Zhang $L$ and Eisenberg A. Science 268 (1995) 1728-1731.

2. Zhang $L$ and Eisenberg A. J. Am. Chem. Soc. 118 (1996) 3168-3181.

3. $\quad$ Zhang L, Yu K, and Eisenberg A. Science 272 (1996) 1777-1779.

4. Zhang L and Eisenberg A. Polym. Adv. Technol. 9 (1998) 677-699.

5. $\quad$ Discher DE and Eisenberg A. Science 297 (2002) 967-973.

6. Mai Y and Eisenberg A. Chem. Soc. Rev. 41 (2012) 5969-5985.

7. Hadjichristidis N, Pispas S, and Floudas G. Block Copolymers: Synthetic Strategies, Physical Properties, and Applications. John Wiley \& Sons, Inc., 2002. pp. 1-27.

8. Lazzari M, Liu G, and Lecommandoux S. Block Copolymers in Nanoscience: Wiley-VCH Verlag GmbH \& Co. KGaA, 2006.

9. Charleux B, Delaittre G, Rieger J, and D'Agosto F. Macromolecules 45 (2012) 6753-6765.

10. Lansalot M, Rieger J, and D'Agosto F. Polymerization-Induced Self-Assembly: the Contribution of Controlled Radical Polymerization to the Formation of Self-Stabilized Polymer Particles of Various Morphologies. In: Borisov $\mathrm{O}$ and Billon L, editors. Macromolecular self-assembly, vol. In press, 2016.

11. Canning SL, Smith GN, and Armes SP. Macromolecules 49 (2016) 1985-2001.

12. Warren NJ and Armes SP. J. Am. Chem. Soc. 136 (2014) 10174-10185.

13. Rieger J. Macromol. Rapid Commun. 36 (2015) 1458-1471.

14. Derry MJ, Fielding LA, and Armes SP. Prog. Polym. Sci. 52 (2016) 1-18.

15. Zhang W, D'Agosto F, Boyron O, Rieger J, and Charleux B. Macromolecules 45 (2012) 4075-4084.

16. Blanazs A, Madsen J, Battaglia G, Ryan AJ, and Armes SP. J. Am. Chem. Soc. 133 (2011) 1658116587.

17. Sun J-T, Hong C-Y, and Pan C-Y. Soft Matter 8 (2012) 7753-7767.

18. Sun J-T, Hong C-Y, and Pan C-Y. Polym. Chem. 4 (2013) 873-881.

19. Zhang W, D'Agosto F, Dugas P-Y, Rieger J, and Charleux B. Polymer 54 (2013) 2011-2019.

20. Binauld S, Delafresnaye L, Charleux B, D'Agosto F, and Lansalot M. Macromolecules 47 (2014) 34613472.

21. Carlsson L, Fall A, Chaduc I, Wagberg L, Charleux B, Malmstrom E, D'Agosto F, Lansalot M, and Carlmark A. Polym. Chem. 5 (2014) 6076-6086.

22. St Thomas C, Guerrero-Santos R, and D'Agosto F. Polym. Chem. 6 (2015) 5405-5413.

23. Chaduc I, Zhang W, Rieger J, Lansalot M, D'Agosto F, and Charleux B. Macromol. Rapid Commun. 32 (2011) 1270-1276.

24. Chaduc I, Crepet A, Boyron O, Charleux B, D’Agosto F, and Lansalot M. Macromolecules 46 (2013) 6013-6023.

25. Chaduc I, Girod M, Antoine R, Charleux B, D'Agosto F, and Lansalot M. Macromolecules 45 (2012) 5881-5893.

26. Zhang W, D'Agosto F, Boyron O, Rieger J, and Charleux B. Macromolecules 44 (2011) 7584-7593.

27. Draget KI, Smidsrod O, and Skjak-Braek G. Alginates from algae. Polysaccharides II. Polysaccharides from Eukaryotes, vol. 6, 2002. pp. 215-244.

28. Rehm BHA. Alginates from bacteria. In: Vandamme EJ, De Baets $S$, and Steinbüchel A, editors. Polysaccharides II: Polysaccharides from Eukaryotes, vol. 6. Weinheim: Wiley-VCH, 2002. pp. 179212.

29. Aarstad OA, Tøndervik A, Sletta H, and Skjåk-Bræk G. Biomacromolecules 13 (2012) 106-116. 
30. Smidsroed O. Faraday Discuss. Chem. Soc. 57 (1974) 263-274.

31. Morris ER, Rees DA, Robinson G, and Young GA. J. Mol. Biol. 138 (1980) 363-374.

32. Donati I, Holtan S, Morch YA, Borgogna M, Dentini M, and Skjåk-Bræk G. Biomacromolecules 6 (2005) 1031-1040.

33. Smidsroed O and Haug A. Acta Chem. Scand. 22 (1968) 1989-1997.

34. Kohn R, Furda I, Haug A, and Smidsroed O. Acta Chem. Scand. 22 (1968) 3098-3102.

35. Kohn R. Pure Appl. Chem. 42 (1975) 371-397.

36. Qin Y. Text. Res. J. 75 (2005) 165-168.

37. Silva RM, Manso JP, Rodrigues JR, and Lagoa RJ. J. Environ. Sci. Heal. A 43 (2008) 1311-1317.

38. Tzu T, Tsuritani T, and Sato K. J. Environ. Prot. 4 (2013) 51-55.

39. Alfaro-Cuevas-Villanueva R, Hidalgo-Vázquez AR, Cortés Penagos CdJ, and Cortés-Martínez R. The Scientific World Journal 2014 (2014) 647512.

40. Haug A and Smidsroed O. Nature 215 (1967) 757.

41. Rinaudo M. Seaweed polysaccharides. In: Kamerling JP, editor. Comprehensive Glycoscience, vol. 2, 2007. pp. 691-735.

42. Wu Y, Mimura H, and Niibori Y. J. Radioanal. Nucl. Chem. 281 (2009) 513-520.

43. Haug A, Larsen B, and Smidsroed O. Acta Chem. Scand. 20 (1966) 183-190.

44. Simensen MK, Draget K, Smidsrod O, and Hjelland F. Production of uronic acid blocks from alginate by hydrolysis and selective fractionation. WO: Norsk Hydro Asa, Norway, 1998. pp. 31.

45. Otterlei M, Ostgaard K, Skjåk-Bræk G, Smidsrod O, Soon-Shiong P, and Espevik T. J. Immunother. 10 (1991) 286-291.

46. Otterlei M, Sundan A, Skjåk-Bræk G, Ryan L, Smidsrod O, and Espevik T. Infect. Imm. 61 (1993) 1917-1925.

47. Bernard J, Save M, Arathoon B, and Charleux B. J. Polym. Sci.: Part A Polym. Chem. 46 (2008) 28452857.

48. Ting SRS, Min EH, Zetterlund PB, and Stenzel MH. Macromolecules 43 (2010) 5211-5221.

49. Hatton $F L$, Ruda $M$, Lansalot $M$, D'Agosto $F$, Malmström E, and Carlmark A. Biomacromolecules (2016) DOI: 10.1021/acs.biomac.1026b00036.

50. Ladmiral V, Semsarilar M, Canton I, and Armes SP. J. Am. Chem. Soc. 135 (2013) 13574-13581.

51. Liu DZ, Chen WP, Lee CP, Wu SL, Wang YC, and Chung TW. J. Microencapsul. 21 (2004) 643-652.

52. Acosta-Torres LS, Barceló-Santana FH, Álvarez-Gayosso CA, and Reyes-Gasga J. J. Appl. Polym. Sci. 109 (2008) 3953-3960.

53. Kapishon V, Whitney RA, Champagne P, Cunningham MF, and Neufeld RJ. Biomacromolecules 16 (2015) 2040-2048.

54. Boursier T, Chaduc I, Rieger J, D'Agosto F, Lansalot M, and Charleux B. Polym. Chem. 2 (2011) 355362.

55. Glycuronan is the generic name for a polysaccharide composed entirely of glycuronic acid residues such as $\beta$-D-mannuronic acid or $\alpha$-L-guluronic acid.

56. McNaught AD. Pure Appl. Chem. 68 (1996) 1919-2008.

57. Albertin L. Protecting-group-free synthesis of well-defined glycopolymers featuring negatively charged oligosaccharides. In: Sun X-L, editor. Macro-Glycoligands - Methods and Protocols: Springer, 2016.

58. Ghadban A, Albertin L, Rinaudo M, and Heyraud A. Biomacromolecules 13 (2012) 3108-3119.

59. Ghadban A, Reynaud E, Rinaudo M, and Albertin L. Polym. Chem. 4 (2013) 4578-4583.

60. Couvreur L, Lefay C, Belleney J, Charleux B, Guerret O, and Magnet S. Macromolecules 36 (2003) 8260-8267.

61. Cunningham VJ, Alswieleh AM, Thompson KL, Williams M, Leggett GJ, Armes SP, and Musa OM. Macromolecules 47 (2014) 5613-5623.

62. Rieger J, Stoffelbach F, Bui C, Alaimo D, Jérôme C, and Charleux B. Macromolecules 41 (2008) 40654068.

63. Rieger J, Osterwinter G, Bui C, Stoffelbach F, and Charleux B. Macromolecules 42 (2009) 55185525. 
64. Rieger J, Zhang W, Stoffelbach F, and Charleux B. Macromolecules 43 (2010) 6302-6310.

65. Velasquez E, Rieger J, Stoffelbach F, Charleux B, D'Agosto F, Lansalot M, Dufils P-E, and Vinas J. Polymer 54 (2013) 6547-6554.

66. Xu J, Xiao X, Zhang Y, Zhang W, and Sun P. J. Polym. Sci., Part A: Polym. Chem. 51 (2013) 1147-1161.

67. Truong NP, Dussert MV, Whittaker MR, Quinn JF, and Davis TP. Polym. Chem. 6 (2015) 3865-3874.

68. Truong NP, Whittaker MR, Anastasaki A, Haddleton DM, Quinn JF, and Davis TP. Polym. Chem. 7 (2016) 430-440.

69. Chaduc I, Lansalot M, D'Agosto F, and Charleux B. Macromolecules 45 (2012) 1241-1247.

70. Haug A and Larsen B. Acta Chem. Scand. 17 (1963) 1653-1662.

71. Favier A, Charreyre M-T, Chaumont P, and Pichot C. Macromolecules 35 (2002) 8271-8280.

72. D'Agosto F, Hughes R, Charreyre M-T, Pichot C, and Gilbert RG. Macromolecules 36 (2003) 621629.

73. Favier A, Charreyre M-T, and Pichot C. Polymer 45 (2004) 8661-8674.

74. Favier $A$, Ladavière $C$, Charreyre $M-T$, and Pichot $C$. Macromolecules 37 (2004) 2026-2034.

75. Bathfield M, D'Agosto F, Spitz R, Charreyre M-T, and Delair T. J. Am. Chem. Soc. 128 (2006) 25462547.

76. de Lambert B, Charreyre M-T, Chaix C, and Pichot C. Polymer 48 (2007) 437-447.

77. Bathfield M, D'Agosto F, Spitz R, Ladavière C, Charreyre M-T, and Delair T. Macromol. Rapid Commun. 28 (2007) 856-862.

78. Bathfield M, Daviot D, D'Agosto F, Spitz R, Ladavière C, Charreyre M-T, and Delair T. Macromolecules 41 (2008) 8346-8353.

79. Jo YS, van der Vlies AJ, Gantz J, Antonijevic S, Demurtas D, Velluto D, and Hubbell JA. Macromolecules 41 (2008) 1140-1150.

80. Albertin L, Wolnik A, Ghadban A, and Dubreuil F. Macromol. Chem. Phys. 213 (2012) 1768-1782.

81. Gody G, Maschmeyer T, Zetterlund PB, and Perrier S. Nature Commun. 4 (2013) Article number: 2505.

82. Lesage de la Haye J, Zhang X, Chaduc I, Brunel F, Lansalot M, and D'Agosto F. Angew. Chem. Int. Ed. 55 (2016) 3739-3743.

83. Atkins EDT, Nieduszynski IA, Mackie W, Parker KD, and Smolko EE. Biopolymers 12 (1973) 18651878.

84. Atkins EDT, Nieduszynski IA, Mackie W, Parker KD, and Smolko EE. Biopolymers 12 (1973) 18791887.

85. Vold IMN, Kristiansen KA, and Christensen BE. Biomacromolecules 7 (2006) 2136-2146.

86. Polymer Handbook, 4th Edition. In: Brandrup J, Immergut EH, and Grulke EA, editors. New York: John Wiley and Sons, Inc., 1999. pp. II.184.

87. Jodra Y and Mijangos F. Water Sci. Technol. 43 (2001) 237-244.

88. Andersson KG and Roed J. J Environ. Radioactiv. 22 (1994) 197-203.

89. Parra RR, Medina VF, and Conca JL. J Environ. Radioactiv. 100 (2009) 923-934.

90. Avramenko V, Bratskaya S, Zheleznov V, Sheveleva I, Voitenko O, and Sergienko V. J. Hazard. Mater. 186 (2011) 1343-1350.

91. Bratskaya S, Musyanovych A, Zheleznov V, Synytska A, Marinin D, Simon F, and Avramenko V. ACS Appl. Mater. Inter. 6 (2014) 16769-16776. 